\title{
Hastanelerde Kurumsal Kaynak Planlaması Sistemlerinin Kabulü ve Kullanımının Genişletilmiş Teknoloji Kabul Modeline Göre Değerlendirilmesi: Ankara İli Örneği
}

Gözde YALÇIN, Öğr. Gör., Yüksek İhtisas Üniversitesi Sağlık Hizmetleri Meslek Yüksekokulu, Ankara-TÜRKIYYE gozdeyalcin@yiu.edu.tr

Zekai ÖZTÜRK, Doç. Dr., Gazi Üniversitesi İktisadi ve İdari Bilimler Fakültesi, Ankara-TÜRKIYYE zozturk@gazi.edu.tr

\section{Evaluation of Admission And Use of Institutional Resource Planning Systems in Hospitals by Enhanced Technology Acceptance Model: Ankara Sample}

ABSTRACT Enterprise resource planning is a generic name given to integrated management systems that enable the efficient use of resources such as labor, machinery and materials required for the production of goods and services in enterprises. Hospital information systems used in the health sector are emerging as a sectoral solution developed to meet the needs of health 
institutions and organizations with the health supplement installed on the core applications provided by the institutional resource planning systems. In this study, information was given about enterprise resource planning systems, hospital use and extended technology adoption model. The aim of this study is to evaluate the adoption and use of the system by the administrative staff and medical secretaries working in a state hospital in education and research in Ankara according to the extended technology adoption model. In this direction, a survey was conducted on a total of 244 people in the education and research hospital in Çankaya, Ankara. Independent Sample T-Test, One-Way ANOVA Analysis and Correlation Analysis were included in the analysis of the data obtained as the result of the application. As a result of the hypotheses formed during the research, it was found that there was no significant difference between participants' evaluations on the acceptance and usability of institutional resource planning systems and the variables such as age, marital status, education level, unit worked, duration of work, and duration of using institutional resource planning system; gender variation was found to be a significant difference. The result is that there is a positive correlation between the extended technology acceptance model variables.

Keywords: Enterprise Resource Planning, Extended Technology Acceptance Model, Hospital.

\section{GíRiş}

Gelişmekte olan, bilgi teknolojileri günümüzde her alanda kullanılmaktadır. Dünya genelinde yaygin olarak kullanılan bilgi teknolojilerinden birisi Kurumsal Kaynak Planlamasıdır (KKP). KKP işletmelerde mal ve hizmet üretimi için gereken işgücü, makine, malzeme gibi kaynakların verimli bir şekilde kullanılmasını sağlayan bütünleşik yönetim sistemlerine verilen genel addır (IAS, tarih yok). KKP kurumun tüm süreçlerinin ve kaynaklarının izlenebilir olmasını amaçlamaktadır. KKP kurumsallaşma yolunda kullanılan bir yazılım olarak düşünülse de, yazılım KKP’nin sadece bir ayağını oluşturmaktadır (ERP Uzmanı, tarih yok). KKP donanım, yazılım ve iletişim ağlarının birleşiminden oluşmaktadır. Örgütteki kontrol ve karar verme mekanizmalarını desteklemek için bilginin toplanması, çıkarılması, işlenmesi, saklanması ve dağıtılmasında birbirleriyle bağlantılı parçaların beraber çalıştıkları bir bütün olarak ifade edilmektedir (Güleryüz, 2007). KKP yazılımları bilişim teknolojilerinin en geniş ve en karmaşık uygulamaları olarak değerlendirilmektedir (Akça ve Özer, 2012).

KKP yazılımları genel olarak çok çeşitli endüstrilerde kullanılmaktadır. Bu kullanım alanlarından biri de sağlık sektörüdür (Akça ve Özer, 2012). Sağlık sektöründe kullanılmakta olan Hastane Bilgi Sistemleri (HBS) , KKP sistemlerinin sunduğu çekirdek uygulamaların üzerine yüklenen sağlık eklentisi ile sağlık kurum ve kuruluşlarının ihtiyaçlarına cevap vermek üzere geliştirilmiş sektörel bir çözüm olarak karşımıza çıkmaktadır. HBS; devlet, üniversite ve özel sektör hastaneleri için gerekli bütün yasal ve yönetimsel işlevleri barındıran, hizmet ve malzeme kaçaklarının önlenmesini, hastaların ve hastane personelinin işlerinin kolaylaştırılarak, işlem akışının hızlandırılması amaçlarını gözeten, yöneticilere çeşitli düzeylerde bilgi ve rapor sunan geniş kapsamlı ve çağdaş bir yönetim bilişim sistemi, karar destek sistemidir (Özoğul, 2008). Bu sistemin kullanıcılar tarafından kabulü ve kullanımı sistem başarısında anahtar rol oynamaktadır. 
Yazına bakıldığında teknoloji kabulünün farklı çerçeveler ve teoriler altında ele alındığı görülmektedir. Teknoloji Kabul Modeli (TKM) bu modellerden biri olarak öne çıkmakta, basitçe bir bilgi sistemleri teorisi olarak ifade edilmektedir. Bu model, insanların bir teknolojiyi nasıl kabul ettiğini açıklamayı ve teorik olarak modellemeyi amaçlamaktadır. TKM, bilişim teknolojilerinin kabulü ve kullanımı ile ilgili en çok benimsenen modeldir (Eriş vd., 2010). Venkatesh ve Davis (2000); Davis'in 1989 yılındaki çalışmasına subjektif norm, imaj, işe uyum, çıktı kalitesi, sonuç gösterilebilirlik, deneyim ve gönüllülük değişkenlerini ekleyerek yeni bir model ortaya çıkarmışlardır. Genişletilmiş bu yeni Teknoloji Kabul Modelini Teknoloji Kabul Modeli 2 (TKM 2) olarak yayınlamışlardır. Teknoloji ne kadar mükemmel olursa olsun, sistem kullanıcılarının teknolojiyi benimsememeleri ve kabul etmemeleri sistemin başarıya ulaşılamayacağını ifade etmektedir. Bu nedenle bilgi sistemlerinin kullanıcılar tarafından kabul edilip edilmediğini anlamak çok önemlidir (Erdem, 2011). KKP projesi başarısızlık riski oldukça yüksek olduğu için, KKP teknolojisi kabulü alanında daha fazla araştırma yapılması gerekmektedir. Bu nedenle bu çalışmada, araştırma yapılan hastanede kullanılan KKP sistemi kabulünde ve kullanımında etkili olan değişkenler TKM 2 çerçevesinde değerlendirilmiştir.

\section{Kurumsal Kaynak Planlama}

İnternet teknolojilerinin yaygın olarak kullanılması, insan hayatının her alanında olduğu gibi, tüm sektörlerde de önemli bir etkiye sahiptir (Zhang vd., 2008). Bu gelişmeleri takiben günümüzde firmalar, rekabette başarılı olmak, değişen iş koşullarını tahmin edebilmek ve bunlara hızlı bir şekilde yanıt verebilmek için işin tüm süreçlerini güçlü ve esnek bir biçimde destekleyen sağlam bilgi sistemlerine ihtiyaç duymaktadırlar. Bu sistemler firmalara iş uygulamalarından ve örgütsel yapılardan lojistik, proje yönetimi, finans, servis, dağıtım, nakliye ve imalata kadar her alanda değişimlere uyum sağlama yeteneği kazandırmaktadır. Bütün bunları KKP ile yapmak mümkündür (Çakmak vd., 2013).

KKP sistemleri, işletmenin faaliyetlerini ve karar alma süreçlerini desteklemek amacıyla kurulan; kapsamında çeşitli yazılım ürünlerini barındıran sistemlerdir. KKP sistemleri tedarik zinciri yönetimi, stok yönetimi, üretim yönetimi, müşteri ilişkileri yönetimi, finansal muhasebe, maliyet ve yönetim muhasebesi, insan kaynakları yönetimi ve diğer veri tabanlı yönetim faaliyetlerini birbirlerine entegre ederek bu faaliyetleri otomatikleştirmektedir (Demir ve Bahadir, 2006).

Başka bir ifade ile KKP, işletmenin, tüm departmanları arasında bütünleşik bir bağ kurarak, veri girişleri ve çıkışları sağlayarak, geniş kapsamlı müdahalelerin yapılabileceği yazılım paketleridir. Kurumun departmanlarını tek bir veri tabanı içerisinde toplayarak bütün çalışanların müşterek veri paylaşımına izin veren bilgisayar sistemi veya sistemleridir (Palanc1, 2013). KKP sistemlerinde yer alan temel fonksiyonlar; Üretim, Mali işler, Dağıtım, İnsan Kaynakları, Satış, Malzeme Yönetimi, Satın Alma, Kalite, Bakım ve Proje Yönetimi olarak siralanabilmektedir. Bu genel kurumsal işlevlerin yanında KKP sistemleri, hastanelerde hastane yönetimi, üniversitelerde öğrenci yönetimi ve perakendecilikte yüksek hacimli ambar yönetimi gibi sektöre özel işlevleri de desteklemektedir (Palancl, 2013). 
KKP yazılımları farklı sektörlerin farklı ihtiyaçlarına uyum sağlayabilecek seviyede özelleştirilebilirler. Bu sebepten dolayı KKP yazılımları 3 farklı biçimde ortaya çıkmaktadır:

- Yazılımın en kapsamlı ve en genel hali olarak, pek çok sektörü hedef alır ve kullanılmadan önce yapılandırılması gerekmektedir.

- Yazılımın kapsamlı halinden önceden yapılandırılmış şablonlar oluşturulabilmekte ve bu şablonlar sektöre ve firma büyüklüğüne göre özelleştirilebilmektedir.

- Yazılım, birinci ve ikinci şekilde yüklendikten sonra firmanın kendi yapısına göre özelleştirilebilmektedir (Yılmaz, 2006).

Günümüzde KKP yazılım firmaları, tüm sektörleri hedef alan genel çözümlerinin yanı sıra, kurulumu esnasında özelleştirilebilen bütünleşik standart yazılım paketleri üzerine yüklenen eklentileri kullanarak sektöre özel çözümler sunmaktadır. Sektörel çözümler çekirdek KKP uygulamalarının, ilgili sektörün ihtiyaçları ve dinamiklerine göre uyarlanmış ve genişletilmiş hali olmaktadır. Sektörel çözümler KKP projelerinin çok daha kısa sürede uygulanabilmesine olanak sağlamakta ve bunun yanında KKP projelerinin başarıya ulaşma yüzdesini yükseltmektedir. KKP sistemlerinin sunduğu çekirdek uygulamaların üzerine yüklenen sağlık eklentisi de, sağlık kurum ve kuruluşlarının ihtiyaçlarına cevap vermek üzere geliştirilmiş sektörel bir çözüm olarak karşımıza çıkmaktadır (Özoğul, 2008). Sağlık kurum ve kuruluşlarında KKP sistemleri uygulamaları, organizasyon için büyük bir risk taşımaktadır, para ve zamana, ayrıca süreç değişikliği ve eğitimde önemli bir yatırım gerektirmektedir (Garg ve Agarwal, 2014). Ancak, Sağlık kurum ve kuruluşları; verimliliği arttırmak, maliyetleri düşürmek, hasta bakımını geliştirmek, sağlık hizmetlerini zamanında ve mümkün olduğunca prosedürlerden, formalitelerden uzak bir şekilde vermek amaciyla bilgisayar tabanlı bilgi sistemlerine yönelmektedirler. Günümüzde bu yönelişin teknolojinin de hızla gelişmesiyle birlikte zorunlu hale geldiği görülmektedir (Koç ve ark., 2012).

\section{Genişletilmiş Teknoloji Kabul Modeli}

İşletmelerin küresel rekabette yerlerini alabilmeleri için tedarik, maliyet, kalite, zaman ve yönetim süreçlerinin her birinde bilişim sistem ve teknolojilerini kullanmaları kaçınılmaz bir ihtiyaç haline gelmiştir (Akbulut, 2015). İşletme yöneticileri, şirketlerini bu süreçler açısından iyileştirebilmek amacıyla çeşitli bilgi teknolojilerine ihtiyaç duymakta ve bu teknolojileri işletmelerinde uygulamaktadırlar (Erdem, 2011). Ancak bu noktada üreticilerin ve tüketicilerin bilişim sistem ve teknolojilerini benimseme sorunlarıyla karşılaşılmaktadır. Bu sebeple, kullanıcılara ileri teknolojiyi benimsemeleri konusuna açıklık getiren çalışmalar yapılmaktadır (Öztürk ve ark., 2011). Bu çalışmalar neticesinde birçok model ortaya çıkmıştır. En çok bilinen modeller, Sebepli Faaliyetler Teorisi, Teknoloji Kabul Modeli, Planlı Davranış Teorisi, Ayrıştırılmış Planlı Davranış Teorisi, Teknoloji Kabul Modeli 2, Delone ve Mclean Bilgi Sistemleri Başarı Modeli ve Yenilik Yayılım Teorisi'dir (Erdem, 2011). Ancak, bu bölüm içerisinde teknoloji kabulü ile ilgili modeller, teknoloji kabul modeli ve teknoloji kabul modeli 2 konularına yer verilmiştir.

Gittikçe artan bilimsel çalışmalarda, bireylerin teknoloji kullanımı, belli teorik modeller yardımıyla ölçülmeye çalışılmaktadır. Bu modellerin en önemlilerinden biri ise, Teknoloji Kabul Modelidir (Turan ve Özgen, 2009). 1989'da Davis tarafından potansiyel kullanıcının 
teknolojik yenilikleri kullanma niyetini açılamak için TKM'nin önerildiği görülmektedir (Lim ve Ting, 2012). TKM bilgi sistemi kullanımını açıklamak amacı ile yaygın olarak kullanılan en popüler teoriler arasında yer almakla kalmayıp, bilgi teknolojilerinin kabulü ve kullanımı açısından en çok kabul gören model olarak benimsenmiştir (Surendran, 2012; Mutlu ve Efeoğlu, 2013). TKM'nin amacı, geniş kapsamiyla bilgisayar teknolojileri ve kullanıcı popülasyonları arasında kullanıcı davranışını açıklayabilen genel bilgisayar teknolojilerini kabul etmenlerinin belirleyicilerine bir açıklama getirmektir (Al-Gahtani ve King, 1999). Teknoloji kabul modeli Şekil 1'de görülmektedir.

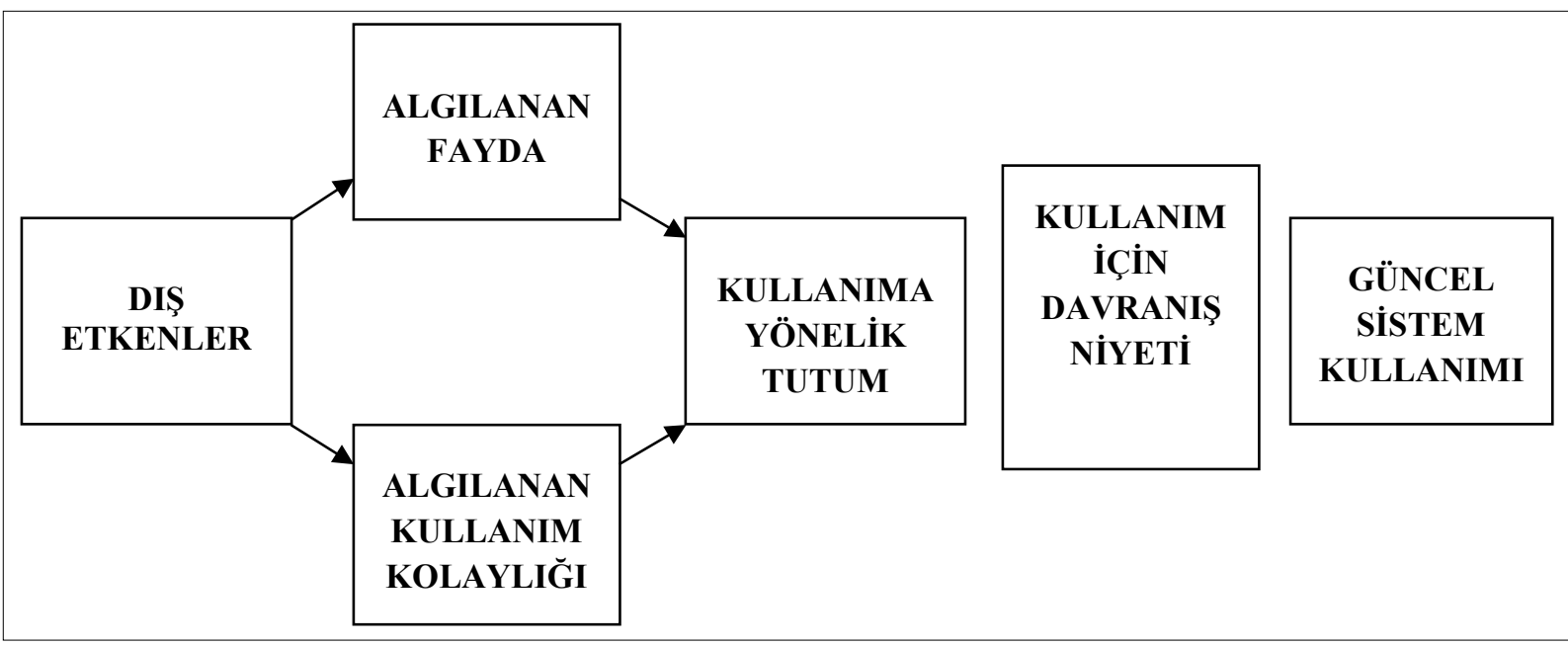

Şekil 1.1. Teknoloji kabul modeli (Masrom, 2007)

Teknoloji Kabul Modelinde, kullanıcı kabulünün iki ana faktör tarafından belirlendiği ileri sürülmektedir. Bu faktörler algılanan fayda ve algılanan kullanım kolaylığı ölçekleridir (Mutlu, 2012). Algılanan fayda, "bir kişinin belli bir sistemi kullanımı sonucu iş performansını arttırdığına inanma derecesi" olarak ifade edilebilmektedir (Davis, F., 1989). Algılanan kullanım kolaylığı "bir kişinin "belirli" bir sistem kullanımında, fiziksel ve zihinsel çaba gerektirmediğine inanma derecesini" ifade etmektedir (Chuttur, M., 2009). Algilanan fayda ve algılanan kullanım kolaylığı, dışsal değişkenler tarafından etkilenmektedir (Erdem, 2011).

2000'de TKM 2, Venkatesh ve Davis tarafından TKM temelinde geliştirilmiştir (Wu ve ark., 2011). Davis'in 1989 yılındaki çalışmasına subjektif norm, imaj, işe uyum, çıktı kalitesi, sonuç gösterilebilirlik, deneyim ve gönüllülük değişkenleri eklenmiştir. Genişletilmiş bu yeni Teknoloji Kabul Modeli'ni Teknoloji Kabul Modeli 2 (TKM 2) olarak adlandırmışlardır. TKM'yi başlangıç noktası olarak kullanan TKM 2, sosyal etki süreçlerini ve bilişsel araç süreçlerini kapsayan ek teorik yapıları birleştirmektedir (Venkatesh ve Davis, 2000). 


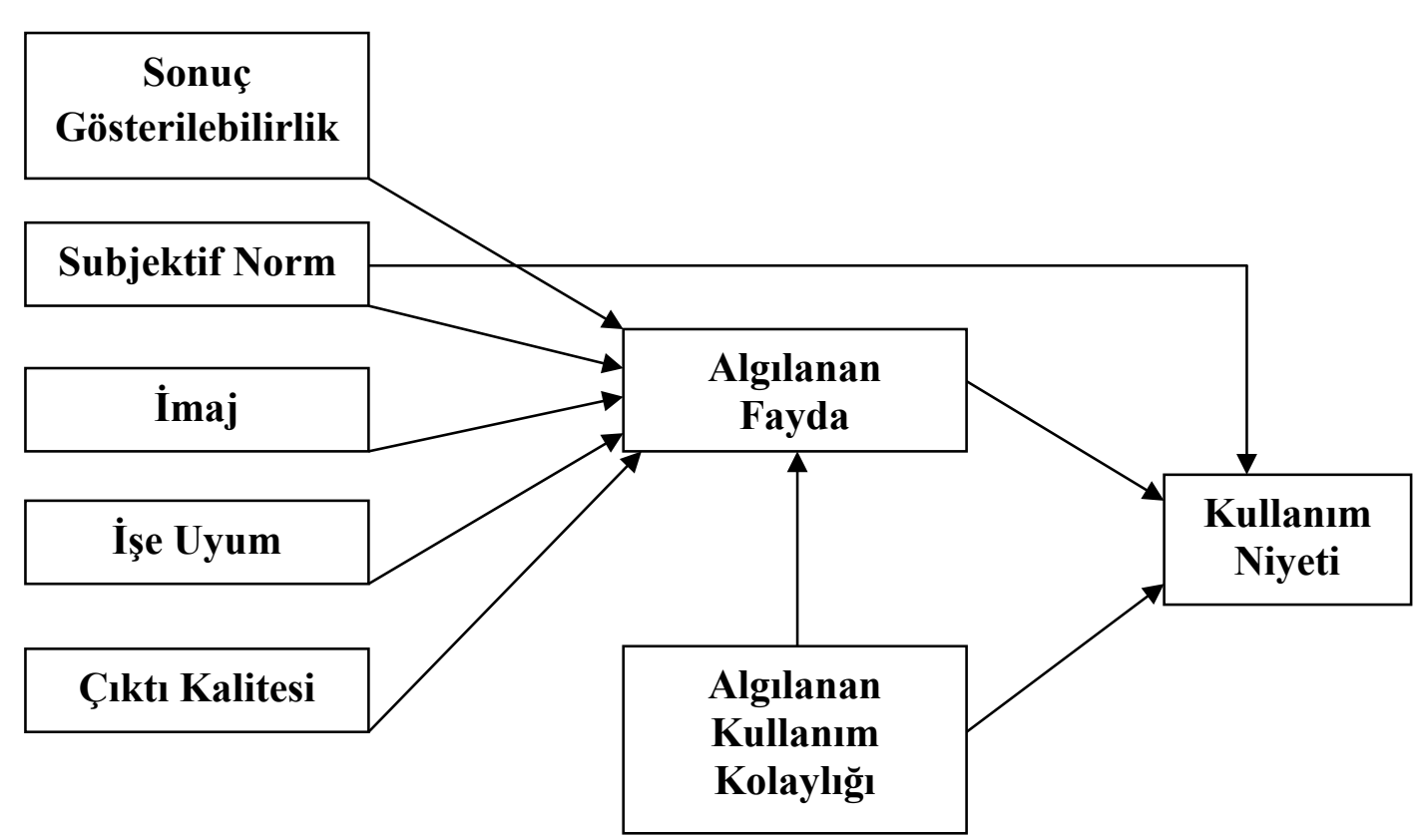

Şekil 1.2. TKM 2 - Genişletilmiş teknoloji kabul modeli (Venkatesh ve Davis, 2000)

Teknoloji Kabul Modeli'ne eklenen değişkenler aşağıda açıklanmaktadır.

Subjektif Norm: Kişinin algısının, onun için önemli olan insanların fikirlerinin davranışa olan etkisini ifade etmektedir (Venkatesh ve Davis, 2000).

İmaj: Kişinin sosyal sisteminde durumunu geliştirmek için bir inovasyonun kullanımının algılanma derecesi olarak tanımlanmaktadır (Moore ve Benbasat,1991).

İse Uyum: Sistemin destekleyebildiği görevler dizisindeki kişinin işinde öneminin bir fonksiyonudur (Venkatesh ve Davis, 2000). Yani kullanıcının, hedef sistemin işine uygun olduğuna inanma derecesidir (Akbulut, 2015).

Çıktı Kalitesi: Çalışanın, kullandığı yeni teknoloji ile işini daha iyi yapacağına inanma derecesidir (Akbulut, 2015).

Sonuç Gösterilebilirlik: Kişinin yeniliğin kullanıldığı sonuçların somutlaşması durumuna inanma derecesi olarak tanımlanmaktadır (Moore ve Benbasat,1991).

Önceki araştırmalarda TKM 2 bilgi teknolojileri kabulünün en etkili, yaygın olarak istihdam edilen ve oldukça öngörülen modeli olarak görüldügü için, bu araştırmada TKM 2 kullanılmak üzere seçilmiştir (Fathema vd. 2015).

\section{YÖNTEM}




\section{Araştırmanın Amacı}

$\mathrm{Bu}$ araştırmanın amacl, araştırmanın yapıldığı KKP sistemi kullanan hastanede kullanıcıların bu sistemi kabulü ve kullanımının genişletilmiş teknoloji kabul modeline göre değerlendirilmesidir. İfade edilen bu amaç doğrultusunda, katılımcıların KKP sistemi algısı ortaya konacak ve bu algılamanın cinsiyet, yaş, medeni durum, öğrenim düzeyi, çalışılan birim, görev, çalışma süresi ve KKP sistemini kullanma süresi değişkenlerine göre anlamlı bir farklılık oluşturup oluşturmadığı ortaya konacaktır. Yine bu çalışmada katılımcıların KKP sistemine ilişkin görüşleri içerisinde yer alan "Kullanım Niyeti, Algilanan Kullanım Kolaylığı, İmaj, Algılanan Fayda, Sonuçların Gösterilebilirliği, Subjektif Norm, İşe Uyum, Çıktı Kalitesi" boyutlarının birbirleri ile olan ilişkisi ortaya konacaktır.

\section{Araştırmanın Önemi}

HBS, sağlık sektörünün ihtiyaçlarına göre donatılmış ve geliştirilmiş KKP sistemleridir. Hastanelerin sorunsuz, kaliteli ve hızlı hizmet sunabilmesi büyük oranda KKP sistemini kabul edip, kullanmalarına ve bu sisteme adaptasyon süreçlerini başarıyla gerçekleştirmelerine yani teknoloji yönetimindeki etkinliklerine bağlıdır. KKP sistemlerinin, kullanıcıların performansını iyileştirdiği bilinmektedir. KKP sistemleri zorlayıcı organizasyonel değişimleri de beraberinde getirmektedir. Bireylerin yeni sistemi kullanmalarına ve kabul etmelerine yönelik tutumları, lehte veya aleyhte sonuçlanabilmektedir. Bu tutumlar adaptasyon veya red kararına yol açarak, sistem performansı üzerinde doğrudan rol oynamaktadır. Bu yüzden birey seviyesinde kullanıma ve kabule etki eden faktörlerin incelenmesi ve etki derecelerinin ortaya konması önem arz etmektedir. Söz konusu problemlerin çözümüne yönelik çok geliştirilen çeşitli teoriler TKM'nin bilgi sisteminin kullanım niyetini önceden tahmin ettiğini ve kullanıcı kabulünü önceden öngördügünü teyit eden çalışmalar bulunmaktadır. Araştırmacıların (Venkatesh ve Davis, 2000) testlerden elde ettikleri bulgulara göre TKM güçlü bir şekilde desteklenmektedir (Akça ve Özer, 2012). Bu çalışmada TKM'nin sosyal etki süreçleri ve bilişsel etki süreçleri değişkenleri ile genişletilmiş şekli olarak tanımlanan TKM 2 kullanılmıştır.

Hastanelerde KKP sistemlerine ilişkin Türkiye'de yapılan çalışmalar oldukça sınırlı kalmıştır. Bilimsel yöntemler kullanılarak yapılan bu çalışmadan elde edilen sonuçlar doğrultusunda sunulan önerilerin araştırmanın yapıldığı hastanede KKP kullanıcılarının ihtiyaçlarının karşılanması, kullanıcılar tarafından sistem kabulü ve sistem kullanımının arttırılması açısından önem taşımakta olup, bundan sonraki araştırmalar için veri sağlaması açısından önemli olduğu düşünülmektedir.

\section{Araştırmanın Yöntemi ve Kapsamı}

Bu çalışmada, betimsel ve ilişkisel bir tarama modeli tercih edilmiş olup, verilerin elde edilmesi amacıyla anket yöntemine başvurulmuştur. Anket uygulamalarının gerçekleştirilmesi ise yüz yüze görüşme ile sağlanmıştır. Anket formunun hazırlanmasında Akbulut tarafından 2015 yılında uygulamış olan anket çalışmasından yararlanılmıştır. 
Yapılan ölçek uygulaması sonucunda elde edilen verilerin çözümlenmesinde SPSS 24 (Statistical Package for the Social Science) paket programından yararlanılmıştır.

Toplam 31 sorudan oluşan Kurumsal Kaynak Planlaması Sistemi Ölçek formunda iki bölüm yer almaktadır.

\section{Birinci bölüm: Kişisel Bilgi Formu}

Birinci bölümde yer alan kişisel bilgi formunda ankete katılanların cinsiyet, yaş, medeni durum, öğrenim düzeyi, çalışılan birim, görev, çalışma süresi ve KKP sistemini kullanma süresi ile ilgili bilgiler yer almaktadır. Toplam 8 sorudan oluşan bu kısımda katılımcı sayıları ve yüzdelik dilimleri yer almaktadır. Araştırmada yer alan bu soruların temel kullanım amacı, ölçek içerisinde yer alan ifadelere göre farklılık oluşturup oluşturmadığının incelenmesidir.

\section{İkinci Bölüm: Kurumsal Kaynak Planlaması Sistemi Ölçeği}

Toplam 23 sorudan oluşan ikinci bölümde yer alan KKP sistemi ölçeğinde ise, "Mümkün olduğu ölçüde Kurumsal Kaynak Planlama sistemi kullanma niyetindeyim.", "KKP sistemi kullanımı kolaydır.", "KKP sistemi kullanmak işimdeki verimliliğimi artırır.", "KKP sistemi kullanmak işimdeki etkinliğimi artırır.", "KKP sistemi kullanmanın sonuçları bana göre açıktır." gibi ifadeler yer almaktadır. Sorularda kullanıcının bir uçtan diğerine değişen yanıt seçeneklerini kullanarak tutum ve davranışları ölçen Likert ölçeği kullanılmıştır (Likert Ölçeğinin Açıklanması). Bu ölçekte yer alan ifadeler, kesinlikle katılmıyorumdan kesinlikle katılıyoruma doğru şekillenmiştir. Örneğin katılımcılar "KKP sistemini işimde faydalı bulurum." Ölçek ifadesi için 1: Kesinlikle Katılmıyorum, 2: Katılmıyorum, 3: Kararsızım, 4: Katılıyorum ve 5: Kesinlikle Katılıyorum şeklinde cevaplarda bulunmuşlardır.

KKP sisteminin kabulü ve sistemin kullanılabilirliğine yönelik değerlendirmeleri üzerinde etkili olan bağımsız değişkenler; cinsiyet, yaş, medeni durum, öğrenim düzeyi, çalışılan birim, görev, çalışma süresi ve KKP sistemini kullanma süresi değişkenlerinden oluşmaktadır. Bağımlı değişken olarak araştırmaya konu olan KKP sisteminin kabulü ve kullanılabilirliğine yönelik değerlendirmeler ise; Kullanım Niyeti, Algılanan Kullanım Kolaylığı, İmaj, Algılanan Fayda, Sonuçların Gösterilebilirliği, Subjektif Norm, İşe Uyum, Çıktı Kalitesi olmak üzere 8 alt boyuttan oluşmaktadır.

\section{Araştırmanın Sınırlılıkları}

Araştırmanın sınırlılıkları;

- Anket uygulaması yapılan personel; bilgisayar işletmeni, memur, veri hazırlama ve kontrol işletmeni, birim şefi, sekreter, hastane müdürü ve hastane müdür yardımcısı unvanları ile sınırlandırılmıştır.

- Bu araştırma, Ankara ilinde bir devlet üniversitesi eğitim ve araştırma hastanesinde uygulama yapılan personelin verdiği cevaplarla sınırlandırılmıştır.

- $\mathrm{Bu}$ araştırmanın sonuçları uygulama yapılan hastane ile sınırlandırılmış olup, araştırma sonuçları genellenemez. 


\section{Araştırmanın Evreni ve Örneklemi}

Araştırmanın evrenini Ankara ilinde hizmet veren bir devlet üniversitesine bağlı eğitim ve araştırma hastanesinin idari personeli oluşturmaktadır. Araştırmaya katılacak olan katılımcıların "bir devlet üniversitesi eğitim ve araştırma hastanesinin idari personeli olma" özelliğini taşıması gerekmektedir. Belirlenen idari personel kapsamına; bilgisayar işletmeni, memur, veri hazırlama ve kontrol işletmeni, birim şefi, sekreter, hastane müdürü ve hastane müdür yardımcısı dâhil edilmektedir. Buradan hareketle uygulama yapılan hastanedeki toplam çalışan idari personel sayısı 323 kişi olarak belirlenmiştir.

$\mathrm{Bu}$ araştırmada istatistiksel açıdan elde edilen verilerin anlamlılık düzeyinin sağlanması amacı ile toplam 264 kişiye anket uygulanmıştır. Ancak, araştırmaya katılanlardan 20 çalışanın anket formunu belirlenen kriterlere göre doldurmadığı tespit edilmiştir. Sonuç olarak, toplam 244 adet anket istatistiksel analize tabi tutulmuştur.

\section{Verilerin Analizi}

KKP sistemindeki ölçek ifadelerinin güvenilirlik katsayısı $\alpha=0,874$ olarak bulunmuştur. Bulunan bu 'Cronbach Alpha' iç tutarlılık katsayısı ölçeğin yüksek derecede güvenilir olduğunu göstermektedir (Tavşancıl, 2006).

Araştırmanın Bulguları

\section{Katılımcılara Ait Genel Betimsel İstatistikler}

Araştırmanın bu kısmında, katılımcıların bazı sosyo-demografik özelliklerine ilişkin elde edilen verilere yer verilecektir. Söz konusu çözümlemeler Frequencies yöntemi ile gerçekleştirilmiş olup Tablo 1.1'de sunulmuştur.

Tablo 1.1. Katılımcıların demografik özellikleri

\begin{tabular}{|c|c|c|c|}
\hline & & Katılımcı Sayısı & Yüzde \\
\hline \multirow{3}{*}{ CINSIYYET } & Kadın & 158 & 64,8 \\
\hline & Erkek & 86 & 35,2 \\
\hline & Toplam & 244 & 100 \\
\hline & & Katılımeı Sayısı & Yüzde \\
\hline \multirow{8}{*}{ YASS } & $20-25$ & 19 & 7,8 \\
\hline & $26-30$ & 31 & 12,7 \\
\hline & $31-35$ & 40 & 16,4 \\
\hline & $36-40$ & 48 & 19,7 \\
\hline & $41-45$ & 70 & 28,7 \\
\hline & $46-50$ & 20 & 8,2 \\
\hline & 50 ve üstü & 16 & 6,6 \\
\hline & Toplam & 244 & 100 \\
\hline & & Katılımcı Sayısı & Yüzde \\
\hline \multirow{4}{*}{ MEDENİ DURUM } & Evli & 172 & 70,5 \\
\hline & Bekâr & 72 & 29,5 \\
\hline & Toplam & 244 & 100 \\
\hline & & Katılımeı Sayısı & Yüzde \\
\hline
\end{tabular}




\begin{tabular}{|c|c|c|c|}
\hline \multirow{7}{*}{ EĞİTIM DURUMU } & İlköğretim & 1 & 0,4 \\
\hline & Lise & 87 & 35,7 \\
\hline & Önlisans & 68 & 27,9 \\
\hline & Lisans & 76 & 31,1 \\
\hline & Y.Lisans & 11 & 4,5 \\
\hline & Doktora & 1 & 0,4 \\
\hline & Toplam & 244 & 100 \\
\hline & & Katılımcı Sayısı & Yüzde \\
\hline \multirow{3}{*}{ ÇALIŞILAN BİRİM } & İdari Birimler & 102 & 41,8 \\
\hline & T1bbi Birimler & 142 & 58,2 \\
\hline & Toplam & 244 & 100 \\
\hline & & Katılımcı Sayısı & Yüzde \\
\hline \multirow{7}{*}{ GÖREVİ } & Bilgisayar İșletmeni & 33 & 13,5 \\
\hline & Memur & 56 & 23 \\
\hline & Veri Hazırlama ve Kontrol İşletmeni & 27 & 11,1 \\
\hline & Birim Şefleri & 7 & 2,9 \\
\hline & Sekreter & 111 & 45,5 \\
\hline & Diğer & 10 & 4,1 \\
\hline & Toplam & 244 & 100 \\
\hline & & Katılımcı Sayısı & Yüzde \\
\hline \multirow{6}{*}{ ÇALIŞMA SÜRESI } & 1 y1ldan az & 9 & 3,7 \\
\hline & $1-3$ y1l & 17 & 7 \\
\hline & $4-6$ y1l & 34 & 13,9 \\
\hline & $7-9$ y1l & 41 & 16,8 \\
\hline & 10 yıl ve üzeri & 143 & 58,6 \\
\hline & Toplam & 244 & 100 \\
\hline & & Katılımcı Sayısı & Yüzde \\
\hline \multirow{6}{*}{$\begin{array}{l}\text { KKP (HBS) PROGRAMI } \\
\text { KULLANMA SÜRESİ }\end{array}$} & 1 y1ldan az & 11 & 4,5 \\
\hline & $1-3$ y1l & 28 & 11,5 \\
\hline & $4-6$ y1l & 49 & 20,1 \\
\hline & $7-9$ y1l & 40 & 16,4 \\
\hline & 10 yıl ve üzeri & 116 & 47,5 \\
\hline & Toplam & 244 & 100 \\
\hline
\end{tabular}

Tablo 1.1 incelendiğinde, araştırmaya katılanların \% 64,8'inin kadın olduğu, \% 28,7'sinin 41-45 yaş aralığında olduğu, \% 70,5' inin evli olduğu, \% 35,7' sinin lise mezunu olduğu, \% $58,2^{\prime}$ sinin tıbbi birimlerde çalıştığı, \% 45,5' inin sekreter olduğu, \% 58,6'sının 10 yıl ve üzeri bir süredir hizmette bulunduğu ve \% 47,5'inin 10 yıl ve üzeri bir süredir sözü edilen programı kullandığı görülmektedir.

Tablo 1.2. TKM 2 boyutları ve kapsadığı ifadeler

\section{Kullanım Niyeti}

Mümkün olduğu ölçüde Kurumsal Kaynak Planlama sistemi kullanma niyetindeyim.

Erişebildiğim her yerde KKP sistemi kullanacağımı düşünüyorum. 


\begin{tabular}{|l|} 
Algılanan Kullanım Kolaylığı \\
\hline KKP sistemi ile istediğim işlemi yapmanın kolay olduğunu düşünürüm. \\
\hline KKP sistemi kullanımı açık ve anlaşılırdır. \\
\hline KKP sistemi kullanımı kolaydır. \\
\hline KKP sistemi ile etkileşimim çok fazla zihinsel çaba harcamamı gerektirmez. \\
\hline İmaj \\
\hline Çalıştığım hastanede KKP sistemi kullananlar yüksek statüye sahiptirler. \\
\hline Çalıştığım hastanede KKP sistemi kullananlar kullanmayanlara göre daha prestijli kabul edilir. \\
\hline Çalıştığım hastanede KKP sistemi kullanıyor olmak statü sembolüdür. \\
\hline Algılanan Fayda \\
\hline KKP sistemi kullanmak işimdeki verimliliğimi artırır. \\
\hline KKP sistemini işimde faydalı bulurum. \\
\hline KKP sistemi kullanmak işimdeki performansımı artırır. \\
\hline KKP sistemi kullanmak işimdeki etkinliğimi artırır. \\
\hline Sonuç Gösterilebilirlik \\
\hline KKP sistemi kullanmaktan elde ettiğim sonuçları başkalarına rahatlıkla anlatabilirim. \\
\hline KKP sistemi kullanarak elde ettiğim sonuçları başkalarına aktarmakta zorlanmam. \\
\hline KKP sistemi kullanmanın sonuçları bana göre açıktır. \\
\hline KKP sistemi kullanmanın neden faydalı olup olamayacağını açıklamakta zorluk çekerim. \\
\hline Subjektif Norm \\
\hline Üst yönetim KKP sistemi kullanmam gerektiğini düşünür. \\
\hline Bağl olduğum birim yöneticisi KKP sistemi kullanmam gerektiğini düşünür. \\
\hline İşe Uyum \\
\hline Yaptığım işte KKP sistemi kullanmak önemlidir. \\
\hline KKP sistemi kullanmak yaptığım işe uygundur. \\
\hline Çıktı Kalitesi \\
\hline KKP sisteminden elde ettiğim işin kalitesi yüksektir. \\
\hline KKP sistemi kullanarak yaptığım işin sonuçlarından memnunum. \\
\hline
\end{tabular}

Tablo 1.3. Tüm boyutların ortalama ve standart değer sonuçları

\begin{tabular}{|lcc|}
\hline \multicolumn{1}{c}{ Boyutlar } & Ortalama & Standart Sapma \\
\hline Kullanım Niyeti & 3,76 & 0,943 \\
\hline Algılanan Kullanım Kolaylığı & 3,67 & 0,945 \\
\hline İmaj & 2,81 & 1,13 \\
\hline Algılanan Fayda & 3,83 & 0,95 \\
\hline Sonuçların Gösterilebilirliği & 3,55 & 0,963 \\
\hline Subjektif Norm & 3,88 & 0,817 \\
\hline İșe Uyum & 3,96 & 0,864 \\
\hline Çıtı Kalitesi & 3,7 & 0,963 \\
\hline Toplam & $\mathbf{3 , 6 5}$ & $\mathbf{0 , 9 4 7}$ \\
\hline
\end{tabular}

Tablo 1.3'te araştırmaya katılanların kurumsal kaynak planlama sistemine ilişkin değerlendirmelerinin bir bütün olarak yer aldığ1 "ortalama ve standart sapma" değerlerini içermektedir. Buna göre, katılımcıların, söz konusu 8 boyut ile ilgili olarak verilen ifadelerden en yüksek düzeyli katılımı İşe Uyum boyutunda yer alan ifadelerle sağladığı, bu boyutu da sırası ile Subjektif Norm, Algılanan Fayda, Kullanım Niyeti, Çıktı Kalitesi, 
Algılanan Kullanım Kolaylığı, Sonuçların Gösterilebilirliği ve İmaj boyutlarının izlediği görülmüştür.

\section{Araştırmanın Hipotezleri}

Araştırmanın bu kısmında, çalışanların kurumsal kaynak planlama sistemine yönelik değerlendirmeleri "cinsiyet, yaş, medeni durum, öğrenim düzeyi, çalışılan birim, görev, çalışma süresi ve KKP sistemini kullanma süresi” değişkenlerine göre anlamlı bir farklılık gösterip göstermediğinin sonuçlarına yer verilmiştir. Buna göre katılımcıların; algılama düzeylerinin karşılaştırılmasına ilişkin çözümlemeleri iki seçenekli sorular için Bağımsız Örneklem T-Testi; ikiden fazla seçeneğe sahip sorularda ise tek yönlü varyans (Anova) analizi ile gerçekleştirilmiştir.

Yine bu çalışmada katılımcıların KKP sistemine ilişkin görüşleri içerisinde yer alan "algılanan fayda" boyutuna yönelik değerlendirmeleri ile sonuç gösterilebilirlik, algılanan kullanım kolaylığı, kullanım niyeti, işe uyum, subjektif norm, imaj, çıktı kalitesi boyutlarına yönelik değerlendirmeler arasındaki ilişki ve kullanım niyeti boyutuna yönelik değerlendirmeleri ile subjektif norm ve algılanan kullanım kolaylığı boyutuna yönelik değerlendirmeler arasındaki ilişki korelasyon analizi ile olduğu ortaya konmuştur.

Tablo 1.4. Katılımciların kurumsal kaynak planlama sistemini kabulü ve sistemin kullanılabilirliğine yönelik değerlendirmeleri ile bağımsız değişkenler arasındaki ilişki

\begin{tabular}{|c|c|c|c|c|c|}
\hline Cinsiyet & $\mathbf{N}$ & $\mathbf{X}$ & ss & $\mathbf{F}$ & $\mathbf{P}$ \\
\hline Kadın & 158 & 3,62 & 0,53 & \multirow{2}{*}{0,716} & \multirow{2}{*}{$0,003 *$} \\
\hline Erkek & 86 & 3,38 & 0,628 & & \\
\hline Yaş & $\mathbf{N}$ & $\mathbf{X}$ & ss & $\mathbf{F}$ & $\mathbf{P}$ \\
\hline 20-25 Yaş Arası & 19 & 3,61 & 0,393 & \multirow{7}{*}{0,544} & \multirow{7}{*}{$0,775^{*}$} \\
\hline 26-30 Yaş Arası & 31 & 3,48 & 0,54 & & \\
\hline 31-35 Yaş Aras1 & 40 & 3,67 & 0,604 & & \\
\hline 36-40 Yaş Arası & 48 & 3,51 & 0,637 & & \\
\hline 41-45 Yaş Arası & 70 & 3,5 & 0,573 & & \\
\hline 46-50 Yaş Aras1 & 20 & 3,57 & 0,38 & & \\
\hline 50 ve üzeri & 16 & 3,49 & 0,799 & & \\
\hline Medeni Durum & $\mathbf{N}$ & $\mathbf{X}$ & SS & $\mathbf{F}$ & $\mathbf{P}$ \\
\hline Evli & 172 & 3,53 & 0,621 & \multirow{2}{*}{2,825} & \multirow{2}{*}{$0,578^{*}$} \\
\hline Bekâr & 72 & 3,57 & 0,459 & & \\
\hline Eğitim Durumu & $\mathbf{N}$ & $\mathbf{X}$ & SS & $\mathbf{F}$ & $\mathbf{P}$ \\
\hline İlköğretim & 1 & 3,54 & , & \multirow{5}{*}{1,137} & \multirow{5}{*}{$0,341^{*}$} \\
\hline Lise & 87 & 3,47 & 0,683 & & \\
\hline Önlisans & 68 & 3,59 & 0,526 & & \\
\hline Lisans & 76 & 3,53 & 0,498 & & \\
\hline Y. Lisans & 11 & 3,86 & 0,424 & & \\
\hline
\end{tabular}


Hastanelerde Kurumsal Kaynak Planlaması Sistemlerinin Kabulü ve Kullanımının Genişletilmiş Teknoloji Kabul Modeline Göre Değerlendirilmesi: Ankara ïli Örneği - G. YALÇIN, Z. ÖZTÜRK

\begin{tabular}{|c|c|c|c|c|c|}
\hline Doktora & 1 & 3,04 & , & & \\
\hline Çalıştığınız Birim & $\mathbf{N}$ & $\mathbf{X}$ & ss & $\mathbf{F}$ & $\mathbf{P}$ \\
\hline İdari Birimler & 102 & 3,52 & 0,571 & \multirow{2}{*}{0,126} & \multirow{2}{*}{$0,642 *$} \\
\hline Tibbi Birimler & 142 & 3,55 & 0,583 & & \\
\hline Göreviniz & $\mathbf{N}$ & $\mathbf{X}$ & ss & $\mathbf{F}$ & $\mathbf{P}$ \\
\hline Bilgisayar İşletmeni & 33 & 3,54 & 0,655 & \multirow{6}{*}{0,849} & \multirow{6}{*}{$0,516^{*}$} \\
\hline Memur & 56 & 3,45 & 0,582 & & \\
\hline Veri Hazırlama ve Kontrol İşletmeni & 27 & 3,59 & 0,553 & & \\
\hline Birim Şefleri & 6 & 3,46 & 0,445 & & \\
\hline Sekreter & 111 & 3,59 & 0,576 & & \\
\hline Diğer & 10 & 3,32 & 0,405 & & \\
\hline Çalışma Süreniz & $\mathbf{N}$ & $\mathbf{X}$ & ss & $\mathbf{F}$ & $\mathbf{P}$ \\
\hline 1 Yildan Az & 9 & 3,54 & 0,377 & \multirow{5}{*}{0,336} & \multirow{5}{*}{$0,854^{*}$} \\
\hline 1-3 Y1l Aras1 & 17 & 3,59 & 0,427 & & \\
\hline 4-6 Y11 Aras1 & 34 & 3,63 & 0,511 & & \\
\hline 7-9 Y11 Aras1 & 41 & 3,52 & 0,606 & & \\
\hline 10 Y1l ve Üzeri & 143 & 3,51 & 0,611 & & \\
\hline KKP Sistemini Kullanma Süreniz & $\mathbf{N}$ & $\mathbf{X}$ & ss & $\mathbf{F}$ & $\mathbf{P}$ \\
\hline 1 Yildan Az & 11 & 3,53 & 0,338 & \multirow{5}{*}{0,308} & \multirow{5}{*}{$0,873 *$} \\
\hline 1-3 Y1l Aras1 & 28 & 3,43 & 0,685 & & \\
\hline 4-6 Y1l Aras1 & 49 & 3,54 & 0,494 & & \\
\hline 7-9 Y11 Aras1 & 40 & 3,58 & 0,598 & & \\
\hline 10 Y11 ve Üzeri & 116 & 3,54 & 0,597 & & \\
\hline
\end{tabular}

Tablo 1.4'de göre, analiz sonucunda bağımsız değişkenler içerisinde yalnızca cinsiyet durumuna göre anlamlı bir farklılık bulunmuştur $\left(\left({ }^{*} \mathrm{P}<0,05\right)\right.$, $\mathrm{p}$ değeri<0,003).

Tablo 1.5. TKM 2 değişkenleri arasındaki ilişki

\begin{tabular}{|c|c|c|c|}
\hline & & Gösterilebilirlik & Algılanan Fayda \\
\hline \multirow{3}{*}{ Sonuç Gösterilebilirlik } & $\mathbf{r}$ & 1 &, $605^{* *}$ \\
\hline & $\mathbf{P}$ & & 0 \\
\hline & $\mathbf{N}$ & 244 & 244 \\
\hline \multirow{4}{*}{ Algılanan Fayda } & $\mathbf{r}$ &, $605 * *$ & 1 \\
\hline & $\mathbf{P}$ & 0 & \\
\hline & $\mathbf{N}$ & 244 & 244 \\
\hline & & İmaj & Algilanan Fayda \\
\hline \multirow{3}{*}{ İmaj } & $\mathbf{r}$ & 1 &, $328 * *$ \\
\hline & $\mathbf{P}$ & & 0 \\
\hline & $\mathbf{N}$ & 244 & 244 \\
\hline \multirow{2}{*}{ Algılanan Fayda } & $\mathbf{r}$ & ,328** & 1 \\
\hline & $\mathbf{P}$ & 0 & \\
\hline
\end{tabular}


AJIT-e: Online Academic Journal of Information Technology

2018- Cilt/Vol: 9 - Sayı/Num: 34

DOI: 10.5824/1309-1581.2018.4.004.x

\begin{tabular}{|c|c|c|c|}
\hline & $\mathbf{N}$ & 244 & 244 \\
\hline & & İşe Uyum & Algılanan Fayda \\
\hline \multirow{3}{*}{ İşe Uyum } & $\mathbf{r}$ & 1 & ,560** \\
\hline & $\mathbf{P}$ & & 0 \\
\hline & $\mathbf{N}$ & 244 & 244 \\
\hline \multirow{3}{*}{ Algılanan Fayda } & $\mathbf{r}$ &, $560 * *$ & 1 \\
\hline & $\mathbf{P}$ & 0 & \\
\hline & $\mathbf{N}$ & 244 & 244 \\
\hline & & Çıktı Kalitesi & Algllanan Fayda \\
\hline \multirow{3}{*}{ Çıktı Kalitesi } & $\mathbf{r}$ & 1 &, $337 * *$ \\
\hline & $\mathbf{P}$ & & 0 \\
\hline & $\mathbf{N}$ & 244 & 244 \\
\hline \multirow{3}{*}{ Algılanan Fayda } & $\mathbf{r}$ & ,337** & 1 \\
\hline & $\mathbf{P}$ & 0 & \\
\hline & $\mathbf{N}$ & 244 & 244 \\
\hline & & $\begin{array}{c}\text { Algilanan Kullanım } \\
\text { Kolaylığı }\end{array}$ & Algılanan Fayda \\
\hline \multirow{3}{*}{ Algılanan Kullanım Kolaylığı } & $\mathbf{r}$ & 1 &, $588 * *$ \\
\hline & $\mathbf{P}$ & & 0 \\
\hline & $\mathbf{N}$ & 244 & 244 \\
\hline \multirow{3}{*}{ Algılanan Fayda } & $\mathbf{r}$ &, $588 * *$ & 1 \\
\hline & $\mathbf{P}$ & 0 & \\
\hline & $\mathbf{N}$ & 244 & 244 \\
\hline & & Kullanım Niyeti & Subjektif Norm \\
\hline \multirow{3}{*}{ Kullanım Niyeti } & $\mathbf{r}$ & 1 &, $601 * *$ \\
\hline & $\mathbf{P}$ & & 0 \\
\hline & $\mathbf{N}$ & 244 & 244 \\
\hline \multirow{3}{*}{ Subjektif Norm } & $\mathbf{r}$ & $601 * *$ & 1 \\
\hline & $\mathbf{P}$ & 0 & \\
\hline & $\mathbf{N}$ & 244 & 244 \\
\hline & & Kullanım Niyeti & Algılanan Fayda \\
\hline \multirow{3}{*}{ Kullanım Niyeti } & $\mathbf{r}$ & 1 &, $543 * *$ \\
\hline & $\mathbf{P}$ & & 0 \\
\hline & $\mathbf{N}$ & 244 & 244 \\
\hline \multirow{3}{*}{ Algılanan Fayda } & $\mathbf{r}$ &, $543 * *$ & 1 \\
\hline & $\mathbf{P}$ & 0 & \\
\hline & $\mathbf{N}$ & 244 & 244 \\
\hline & & Kullanım Niyeti & $\begin{array}{c}\begin{array}{c}\text { Algılanan Kullanım } \\
\text { Kolaylığ }\end{array} \\
\end{array}$ \\
\hline \multirow{3}{*}{ Kullanım Niyeti } & $\mathbf{r}$ & 1 &, $698^{* *}$ \\
\hline & $\mathbf{P}$ & & 0 \\
\hline & $\mathbf{N}$ & 244 & 244 \\
\hline \multirow{2}{*}{ Algılanan Kullanım Kolaylığg } & $\mathbf{r}$ &, $698 * *$ & 1 \\
\hline & $\mathbf{P}$ & 0 & \\
\hline
\end{tabular}


Hastanelerde Kurumsal Kaynak Planlaması Sistemlerinin Kabulü ve Kullanımının Genişletilmiş Teknoloji Kabul Modeline Göre Değerlendirilmesi: Ankara ilii Örneği - G. YALÇIN, Z. ÖZTÜRK

\begin{tabular}{|llcc|} 
& $\mathbf{N}$ & 244 & 244 \\
\hline & & Subjektif Norm & Alglanan Fayda \\
\hline \multirow{2}{*}{ Subjektif Norm } & $\mathbf{r}$ & 1 &, $524^{* *}$ \\
\cline { 2 - 4 } & $\mathbf{P}$ & & 0 \\
\cline { 2 - 4 } & $\mathbf{N}$ & 244 & 244 \\
\hline \multirow{2}{*}{ Algllanan Fayda } & $\mathbf{r}$ &, $524^{* *}$ & 1 \\
\cline { 2 - 4 } & $\mathbf{P}$ & 0 & 244 \\
\hline **. Correlation is significant at the 0.01 & & & \\
level (2-tailed). & & & \\
\hline
\end{tabular}

Tablo 1.5. değerlendirildiğinde bütün TKM 2 değişkenleri arasında pozitif yönlü ve anlamlı bir ilişki olduğu ortaya çıkmıştır.

$\mathrm{Bu}$ analizler sonucunda, aşağıdaki hipotezler test edilmiştir:

Tablo 1.6. Hipotezlerin değerlendirilmesi

\section{H1: KKP sisteminin kabulü ve kullanılabilirliği konusunda araştırma KISMEN kapsamındaki çalışanlar arasında anlamı bir farklılık vardır. \\ KABUL}

H1a: Katılımcıların kurumsal kaynak planlama sistemini kabulü ve sistemin kullanılabilirliğine yönelik değerlendirmeleri cinsiyete göre anlamlı bir farklılık oluşturmaktadır.

H1b: Katılımciların kurumsal kaynak planlama sistemini kabulü ve sistemin kullanılabilirliğine yönelik değerlendirmeleri yaşa göre anlamlı bir farklılık RED oluşturmaktadır.

H1c: Katılımcıların kurumsal kaynak planlama sistemini kabulü ve sistemin kullanılabilirliğine yönelik değerlendirmeleri medeni duruma göre anlamlı bir farklılık olușturmaktadır.

H1d: Katılımcıların kurumsal kaynak planlama sistemini kabulü ve sistemin kullanılabilirliğine yönelik değerlendirmeleri öğrenim düzeyine göre anlamlı bir farklılık oluşturmaktadır.

H1e: Katılımcıların kurumsal kaynak planlama sistemini kabulü ve sistemin kullanılabilirliğine yönelik değerlendirmeleri çalışılan birime göre anlamlı bir farklılık oluşturmaktadır.

H1f: Katılımc1ların kurumsal kaynak planlama sistemini kabulü ve sistemin kullanılabilirliğine yönelik değerlendirmeleri göreve göre anlamlı bir farklılık oluşturmaktadır.

H1g: Katılımcıların kurumsal kaynak planlama sistemini kabulü ve sistemin kullanılabilirliğine yönelik değerlendirmeleri çalışma süresine göre anlamlı bir farklılık oluşturmaktadır. 
H1h: Katılımcıların kurumsal kaynak planlama sistemini kabulü ve sistemin kullanılabilirliğine yönelik değerlendirmeleri KKP sistemini kullanma süresine göre RED anlamlı bir farklılık oluşturmaktadır.

\begin{tabular}{|ll|}
\hline H2: Genişletilmiş Teknoloji Kabul Modeli değişkenleri arasında anlamlı bir & KABUL \\
ilişki vardır. & \\
\hline H2a: Sonuç gösterilebilirlik ile algılanan fayda arasında anlamlı bir ilişki vardır. & KABUL \\
\hline H2b: İmaj ile algılanan fayda arasında anlamlı bir ilişki vardır. & KABUL \\
\hline H2c: İşe uyum ile algılanan fayda arasında anlamlı bir ilişki vardır. & KABUL \\
\hline H2d: Çıktı kalitesi ile algılanan fayda arasında anlamlı bir ilişki vardır. & KABUL \\
\hline $\begin{array}{l}\text { H2e: Algılanan kullanım kolaylığı ile algılanan fayda arasında anlamlı bir ilişki } \\
\text { vardır. }\end{array}$ & KABUL \\
\hline H2f: Subjektif norm ile kullanım niyeti arasında anlamlı bir ilişki vardır. & KABUL \\
\hline H2g: Algılanan fayda ile kullanım niyeti arasında anlamlı bir ilişki vardır. & KABUL \\
\hline $\begin{array}{l}\text { H2h: Algılanan kullanım kolaylığı ile kullanım niyeti arasında anlamlı bir ilişkiki } \\
\text { vardır. }\end{array}$ & KABUL \\
\hline H21: Subjektif norm ile algılanan fayda arasında anlamlı bir ilişki vardır. & KABUL \\
\hline
\end{tabular}

\section{SONUÇ VE ÖNERİLER}

Kullanıcılar bilgi teknolojisi yeniliklerini kabul etmediklerinden, bilgi teknolojisine yapılan yatırım ile üretkenlik kazanımı arasında çelişkili bir ilişki ortaya çıkmaktadır. Çeşitli araştırmalar, yeni bilgi teknolojilerinin kullanıcı tarafından kabul edilmesini açılamaya ve tahmin etmeye çalışmıştır (Agarwal ve Prasad, 1997). Bireylerin teknoloji kabulünü araştırmak ve belirlemek, hem bu alandaki teorinin gelişmesi açısından hem de bireysel ve toplumsal açıdan önemli olduğundan, toplumsal açıdan; Sağlık Bakanlığı tarafından çalışanlarının HBS uygulamalarını neden kullanıp kullanmadıklarını tespit edip ve sürekli olarak daha gelişmiş ve etkin HBS'ler üretmesi için önemlidir.

$\mathrm{Bu}$ çalışmada, araştırma yapılan hastanede ankete katılan katılımcıların KKP sistemi kabul ve kullanımlarına yönelik olarak, TKM'nin sosyal etki süreçleri ve bilişsel etki süreçleri değişkenleri ile genişletilmiş şekli olarak tanımlanan TKM 2 kullanılmıştır. Literatürdeki bu konudaki boşluğu doldurarak, literatüre katkı sağlamak amaçlanmıştır (Akbulut, 2015).

Analiz sonuçları detaylı bir şekilde incelendiğinde, bağımsız değişkenler içerisinde yalnızca cinsiyet değişkeni ile katılımcıların kurumsal kaynak planlama sistemlerini kabulü ve sistemin kullanılabilirliğine yönelik değerlendirmeleri arasında anlamlı bir farklılık oluşturduğu görülmüştür. Bu araştırmada ayrıca, yapılan ilişki çözümlemeleri sonucunda ise ilişki olup olmadığı incelenen TKM 2 değişkenleri arasında pozitif yönlü ve anlamlı bir ilişki olduğu ortaya çıkmıştır.

İmaj değişkenin ortalama değerinin 2,81 ile düşük çıtı̆̆ı görülmektedir. Katılımcılar kullanmakta oldukları KKP sisteminin bir prestij ve yüksek statü sembolü olmadığını düşünmektedir. Hastane yönetim kadrosu dahil tüm hastane personelinin aynı sistemi kullanıyor olması bu sonucun nedenini ortaya koymaktadır. İşe Uyum değişkeninin 
ortalama değeri 3,96 ile Subjektif Norm değişkenin ortalama değerinin ise 3.88 ile yüksek çıtı̆̆ı görülmektedir.

Sonuçlara göre aşağıdaki önerilerde bulunulabilir:

- KKP sisteminin kullanıcılar tarafından karmaşık algılanmamasında kullanılabilecek en önemli araç eğitimdir. Eğitim, kullanıcıların sisteme yönelik önyargılarını yıkar. Sisteme ilişkin güncelleme, bilgilendirme, eğitim, teknik ve uzaktan destek konularında ihtiyaç olması halinde devamlı desteklenecekleri konusunda güvence verilmelidir.

- Kullanıcinin kullandığı sistemin işine uygun olduğunu düşünmesi işteki verimi artırarak daha doğru sonuçlara ulaşmasını sağlayacağı için önemlidir. Çalışılan sektöre göre, kuruma göre en uygun sistemler tercih edilmelidir.

- Sosyal çevre, insanların bir teknolojiyi kullanması konusundaki algıları üzerinde oldukça etkilidir. Başarıya ulaşabilmek için çalışanların sosyal çevresinden bu teknoloji ile ilgili olumlu haberler alması sağlanmalıdır. Bu noktada yönetim kadrosu ve iş arkadaşları kritik rol oynamaktadır.

- Sistemin kuruma ve kullanıcılara yönelik kazanımları, faydaları açık bir şekilde ifade edilmelidir. Bu konu yöneticiler ve iş arkadaşları kritik rol oynamaktadır. Konu yalnızca teknik açıdan ele alınmamalı ve insan etmeni göz ardı edilmemelidir.

İleride yapılacak olan çalışmalarda aşağıdakiler uygulanabilir:

- Yalnızca KKP sistemi uygulama sürecinin değil KKP sistemine geçiş sürecinin de inceleneceği kapsamlı bir çalışma yapılabilir.

- Araştırma yapılacak olan hastanede, KKP sistemi uygulama sürecinde tıbbi ve idari birimleriyle bir bütün olarak ele alınarak incelenebilir.

- Ayn KKP sistemini kullanan hastaneler arasında sistemin kabul ve kullanımına yönelik olarak karşılaştırmalar yapılabilir.

- Çalışmaya dahil edilmeyen ancak literatürde TKM 2 değişkenleri arasında yer alan, deneyim ve gönüllük gibi değişkenler bulunmaktadır. Algılanan fayda ve kullanım niyeti değişkenlerine doğrudan etkisi olmadığı için çalışmaya dahil edilmemişlerdir. İleride yapılacak olan çalışmalarda bütün değişkenler dahil edilerek daha kapsamlı bir çalışma yapılabilir.

\section{KAYNAKÇA}

Agarwal, R., \& Prasad, J. (1997). The Role of Innovation Characteristics and Perceived Voluntariness in the Acceptance of Information Technology. Decision Science, 28(3), 1.

Akbulut, M. (2015). İşletmelerde Kurumsal Kaynak Planlaması Sistemlerinin Kabulü ve Kullanımının Genişletilmiş Teknoloji Kabul Modeline Göre Değerlendirilmesi. Yüksek Lisans Tezi, Osmaniye Korkut Ata Üniversitesi Sosyal Bilimler Enstitüsü, Osmaniye. 
Akça, Y., \& Özer, G. (2012). Teknoloji Kabul Modeli'nin Kurumsal Kaynak Planlaması Uygulamalarında Kullanılması. Business and Economics Research Journal, 3(2), 80.

Al-Gahtani, S., \& King, M. (1999). Attitudes, Satisfaction And Usage: Factors Contributing To Each in The Acceptance of İnformation Technology. Behaviour and Information Technology, 18(4), 278.

Chuttur M.Y. (2009). Overview of the Technology Acceptance Model: Origins, Developments and Future Directions. Indiana University, USA . Sprouts: Working Papers on Information Systems, 9(37), 5.

Çakmak, Z., Taşkın, E., \& Şaylan, O. (2013). Kurumsal Kaynak Planlaması (Erp) Sisteminde Kritik Başarı Faktörlerinin Belirlenmesine Yönelik Bir Araştırma. Akademik Bakış Dergisi, Sayı:35, 2.

Davis, F. (1989). Perceived Usefulness, Perceived Ease of Use, and User Acceptance of Infarmation Technology. MIS Quarterly, 13(3), 320.

Demir, E., \& Bahardır, O. (2006). Kurumsal Kaynak Planlaması (Erp) Sistemlerinin Maliyetlere ve İşletme Performansına Etkileri. Muhasebe-Bilim Dünyası Dergisi, 8(3), 4-7-8.

Erdem, H. (2011). Kurumsal kaynak planlama sistemlerinin kullanımında etkili olan faktörlerin genişletilmiş teknoloji kabul modeli ile incelenmesi. Doktora Tezi, İstanbul Teknik Üniversitesi Fen Bilimleri Enstitüsü, İstanbul.

Eriş, E.D., Özmen Timurcanday, Ö.N. \& Süral, P. (2010). Bilişim Teknolojilerinin Kabulünde Kişisel Yenilikçilik Bilişim Teknoloji Kaygısı ve Özyeterlilik İle Demografik Değişkenlerin Rolüne İlişkin Yapısal Modelleme. 18. Ulusal Yönetim ve Organizasyon Kongresi. Türkiye.

ERP Uzmanı, (tarih yok). www.erpuzmani.com. 25.07.2017 tarihinde http://www.erpuzmani.com/erp-kurumsal-kaynak-planlamasi-nedir/ adresinden alınd 1

Fathema, N., Shannon, D. \& Ross, M. (2015). Expanding The Technology Acceptance Model (TAM) to Examine Faculty Use of Learning Management Systems (LMSs) In Higher Education Institutions. MERLOT Journal of Online Learning and Teaching, 11(2), 212.

Garg, P., \& Agarwal, D. (2014). Critical Success Factors For ERP İmplementation in A Fortis Hospital: An Empirical Investigation. Journal of Enterprise Information Management, 27(4), 403-404.

Güleryüz, Ö. (2007). Kurumsal Kaynak Planlaması (ERP) ve İşletmelerin Yönetsel Kararlarına Etkileri. Yüksek Lisans Tezi, Dokuz Eylül Üniversitesi Sosyal Bilimler Enstitüsü, İzmir.

Industrial Application Software, (tarih yok). www.ias.com.tr. 25.07.2017 tarihinde http://www.ias.com.tr/tr/Content/erp-kurumsal-kaynak-planlamasi adresinden alındı

Koç, E., Şengül, Y., Özkaya, A. \& Gökçe, B. (2012). Klinik Karar Destek Sistemleri Kullanımına Yönelik Bir Araştırma: Acıbadem Hastanesi Örneği. Tıp Bilişimi Derneği 2012 Kongresi. Türkiye.

Lim, W.M., \& Ting, D.H. (2012). E-shopping: an Analysis of the Technology Acceptance Model. Modern Applied Science, 6(4), 50. 
Moore, G., \& Benbasat, I. (1991). Development of an Instrument to Measure the Perceptions of Adopting an Information Technology Innovation. Information Systems Research, 2(3), 195-203.

Mutlu, S. \& Efeoğlu, İ. (2013). Evaluation of E-Mail Usage by Extended Technology Acceptance Model. International Review of Management and Marketing, 3(3), 113.

Özoğul, C. (2008). Kurumsal Kaynak Planlaması Sistemlerinin Değerlemesinde Reel Opsiyon Yaklaşımı: Hastane Bilgi Sistemi Uygulaması. Doktora Tezi, İstanbul Teknik Üniversitesi Fen Bilimleri Enstitüsü, İstanbul.

Öztürk, Z., Şaklak, Ö. \& Yılmazer, Ö. (2011). Örgütlerde Teknoloji Yönetiminin Kurumsal Etkinliği Sağlamadaki Rolü ve Teknoloji Kabul Modeli, 2. International Conference on New Trends in Education and Their Implications (ss. 191-201). Ankara: Siyasal Kitabevi.

Palanc1, Y. (2013). Kurumsal Kaynak Planlama (ERP) Sistemlerine Giriş ve Uygulamaları. Yüksek Lisans Tezi, İstanbul Ticaret Üniversitesi Fen Bilimleri Enstitüsü, İstanbul.

Surendran, P. (2012). Technology Acceptance Model: A Survey of Literature. International Journal of Business and Social Research, 2(4), 176.

Likert Ölçeğinin Açılaması (tarih yok). tr.surveymonkey.com. 21.06.2017 tarihinde https://tr.surveymonkey.com/mp/likert-scale/ adresinden alındı

Tavşancil, E. (2006). Tutumların Ölçülmesi ve SPSS Veri Analizi. Ankara: Nobel Yayın Dağıtım.

Turan, A., \& Özgen, F. (2009). Türkiye'de E-Beyanneme Sisteminin Benimsenmesi: Geliştirilmiş Teknoloji Kabul Modeli İle Ampirik Bir Çalışma. Doğuş Üniversitesi Dergisi, 10(1), 138-139.

Venkatesh, V., \& Davis, F. (2000). A Theoretical Extension of the Technology Acceptance Model: Four Longitudinal Field Studies. Management Science, 46(2), 186-187-188-191198.

Wu, ., Chou, H., Weng, Y. \& Huang, Y. (2011). TAM2-based Study of Website User BehaviorUsing Web 2.0 Websites as an Example. Wseas Transactions On Business and Economics, 4(8), 136.

Yılmaz, H. (2006). Kurumsal Kaynak Planlaması Uygulamalarında Karşılaşılan Zorluklar ve Çözüm Önerileri Bir İşletmede Uygulaması. Yüksek Lisans Tezi, İstanbul Teknik Üniversitesi Fen Bilimleri Enstitüsü, İstanbul.

Zhang, S., Zhao, S. \& Tan, W. (2008). Extending TAM for Online Learning Systems: An Intrinsic Motivation Perspective. Tsinghua Science And Technology, 13(3), 312. 